Olympic Book of Sports Medicine A. Dirix, H.G. Knuttgen, K. Tittel Blackwell Scientific Publishers (1988). ISBN 0632 019638, 692 pp $£ 39.50$

The Olympic Book of Sports Medicine is subtitled the Encyclopaedia of Sports Medicine. Juan Antonio Samaraach, the President of the International Olympic Committee, in his preface states that the aim of the book is to present an up to date general reference book. Further volumes on more specialized topics are to be added.

The book is 700 pages long with plenty of colour pictures, diagrams and charts of good quality. More than 50 authors contribute to a very wide spread of subjects, in thirteen parts.

The sections dealing with physiology are written to an advanced level. The musculoskeletal system chapter in particular is packed with information of degree standard. Over 50 references are quoted, with some up to date concepts discussed. The use of so many authors means that others have not aimed their texts at such a high level. The chapter on the respiratory system is much shorter and not as up to date; all the references bar one are from the 1960 s. There is no discussion of the effects of training, and the statement is made that the maximal ventilatory capacity is never reached in maximal dynamic exercise. I believe this is very debatable; his athletes are not training hard enough!

The section on environmental conditions is written by R.J. Shephard and therefore more uniform in detail, but given the very wide range of problems the modern sportsman has to adapt to, I would have liked a fuller discussion of heat and altitude acclimatization.

Physical training includes some overlap with the physiology chapters but includes a section on flexibility and is written to a high standard.

I am pleased to see whole sections devoted to training children and females and sport for the elderly. Though with regard to children I was amazed to read a list of diseases considered to be absolute contraindications to playing sports by the Czechoslovak Ministry of Health. Epilepsy, diabetes mellitus and blindness are included with deafness, dermatological conditions, asthma, renal stones all relative contra-indications. A lot of top sportsmen and women would thus be excluded from sport. These lists are just five pages after another list outlining the benefits of sport for similar con-

(C) 1989 Butterworth \& Co (Publishers) Ltd 0306-3674/89/030197-02 \$03.00 ditions! The editors should also have been more ruthless with one Japanese author who drew some very strange and incorrect conclusions concerning exercise for the elderly in direct contradiction to other authors.

One hundred and forty pages are devoted to sports injuries. It was good to see causes of sports injuries covered, though there are glaring omissions in that no mention is made of training methods, or the role of sports medicine in changing the rules of a game or the equipment used. Some chapters are fuller than others, the section on joint injuries is quite superficial.

The use of exercise in prevention and management of internal disease has its own very useful section.

Sports psychology and overtraining are only given a very brief mention in the team care section, but Costill supplies an excellent chapter on nutrition.

The section on doping emphasises to me the differences in belief between the scientists and competitors on the effectiveness of anabolic steroids. Blood doping is not adequately covered.

I am disappointed that there is no place for a section on sport for the disabled.

That English is not the first language of all the editors is evident in places, but the text is generally very readable. The book covers a vast range of subjects and discusses many topical issues. The sections'on sports science assume a good deal of prior knowledge; I do not think this is a book for the layman. However, for the health professional or sports scientist wanting a comprehensive textbook on the whole of sports medicine, this is a good book to have. The Olympic Book of Sports Medicine should certainly be standard reading for anyone taking a Diploma in Sports Medicine.

Roger Hackney Dip. Sports Med.

\section{Principles of Exercise}

Biochemistry (Medicine in Sport)

Ed. J.R. Poortmans. Karger, Basel. 260pp, 1988, ISBN 3-8055-4790-0

This book comprises a comprehensive review of exercise biochemistry, split into 10 chapters, each written by expert authors from different centres around the globe.

The main themes are: muscle contraction and composition; metabolic regulation and utilization of different fuels and a more heterogenous section on types of event; fatigue and metabolic disorders. Each chapter has its own reference section. The latest references used seem to be 1986 with this book being first published in April 1988.

There are some very clear explanations of the different sources of energy available to the sprinter, middle and long distance runners and principles required to obtain best performance.

This book will be a useful asset to any sports doctor and will prove invaluable to the biochemist approaching sports medicine for the first time, although some chapters, notably the contribution on 'Metabolic Limitations in Athletes' can be usefully read by the non-scientific athlete - e.g. 'it may be necessary to increase the intake of liquid to avoid dehydration. A simple means of testing this is to observe the colour of urine - it should be clear not amber.' An excellent review of this field.

M. Howell MCB, MRCPath

Science and Football. Proceedings of 1st World Congress of Science and Football

Eds T. Reilly, A. Lees, K. Davids and W.J. Murphy

E. and F. Spon, London, 651 pp, $£ 26.50$

This book is a series of articles from the Proceedings of the First World Congress of Science and Football held in 1987. They number 88 in all and cover 650 pages. Topics are as diverse as nutrition for the elite footballer, the physiology of training, the match analysis, biomechanics, environment, equipment, the sociological and psychological aspects of football and many more. Although the ubiquitous $\mathrm{VO}_{2}$ max. makes its customary (several) appearances there is no need for the non-scientist to be daunted by this book, for the wealth of fascinating data makes excellent reading for anyone remotely interested in sport - never mind football alone. (Incidentally a pleasing feature is the universal coverage of soccer, rugby, American, Australian and Gaelic football as a happy family).

Injuries are mentioned in the introduction but largely omitted in the text apart from a chapter on Achilles tendinitis. However, I greatly enjoyed this series of articles and find it encouraging that so many scientific disciplines are now engaged in analysing, researching, computing and thus enhancing these sports, which after all are the most popular on Earth. I 